\title{
Correction to: miRNA-23b as a biomarker of culture-positive neonatal sepsis
}

\author{
Ahlam Fatmi ${ }^{1}$, Sid Ahmed Rebiahi ${ }^{2}$, Nafissa Chabni ${ }^{3}$, Hanane Zerrouki ${ }^{2}$, Hafsa Azzaoui ${ }^{1}$, Yamina Elhabiri ${ }^{2}$ \\ Souheila Benmansour ${ }^{1,4}$, José Santiago Ibáñez-Cabellos ${ }^{5,6,7}$, Mohammed Chems-Eddine Smahi i,4, \\ Mourad Aribi ${ }^{1}$, José Luis García-Giménez ${ }^{5,6,7}$ and Federico V. Pallardó ${ }^{5,6,7^{*}}$
}

\section{Correction to: Molecular Medicine (2020) 26:94 https://doi.org/10.1186/s10020-020-00217 $-8$}

Following publication of the original article (Fanti et al. 2020), the authors identified an error in the author name of Souheila Benmansour.

The incorrect author name is: Souheila Benmassour.

The correct author name is: Souheila Benmansour.

Also, the authors Souheila Benmansour and Mohammed Chems-Eddine Smahi were affiliated incorrectly.

The correct affiliation for Souheila Benmansour is:

${ }^{1}$ Laboratory of Applied Molecular Biology and Immunology, W0414100 Tlemcen, Algeria.

${ }^{4}$ Neonatal Department of Specialized Maternal and Child Hospital of Tlemcen, 13,000 Tlemcen, Algeria.

The correct affiliation for Mohammed Chems-Eddine Smahi is:

${ }^{1}$ Laboratory of Applied Molecular Biology and Immunology, W0414100 Tlemcen, Algeria.

${ }^{4}$ Neonatal Department of Specialized Maternal and Child Hospital of Tlemcen, 13,000 Tlemcen, Algeria.

The original article has been corrected.

\begin{abstract}
Author details
${ }^{1}$ Laboratory of Applied Molecular Biology and Immunology, W0414100 Tlemcen, Algeria. ${ }^{2}$ Laboratory of Microbiology Applied in Food, Biomedical and Environment, Tlemcen, Algeria. ${ }^{3}$ Faculty of Medicine, Tlemcen Medical Centre University, 13000 Tlemcen, Algeria. ${ }^{4}$ Neonatal Department of Specialized Maternal and Child Hospital of Tlemcen, 13000 Tlemcen, Algeria. ${ }^{5}$ Center for Biomedical Network Research on Rare Diseases (CIBERER), Institute of Health Carlos III, Valencia, Spain. ${ }^{6}$ Mixed Unit for Rare Diseases INCLIVA-CIPF, INCLIVA Health Research Institute, Valencia, Spain. ${ }^{7}$ Department of Physiology, Faculty of Medicine and Dentistry, University of Valencia, Avenida Blasco Ibañez 15, 46010 Valencia, Spain.
\end{abstract}

Published online: 14 December 2020

Reference

Fatmi, et al. Mol Med. 2020;26:94. https://doi.org/10.1186/s10020-020-00217-8.

\section{Publisher's Note}

Springer Nature remains neutral with regard to jurisdictional claims in published maps and institutional affiliations.

*Correspondence: federico.v.pallardo@uv.es

${ }^{5}$ Center for Biomedical Network Research on Rare Diseases (CIBERER),

Institute of Health Carlos III, Valencia, Spain

Full list of author information is available at the end of the article

Mourad Aribi is senior author.

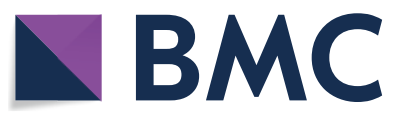

(2020. Open Access This article is licensed under a Creative Commons Attribution 4.0 International License, which permits use, sharing, adaptation, distribution and reproduction in any medium or format, as long as you give appropriate credit to the original author(s) and the source, provide a link to the Creative Commons licence, and indicate if changes were made. The images or other third party material in this article are included in the article's Creative Commons licence, unless indicated otherwise in a credit line to the material. If material is not included in the article's Creative Commons licence and your intended use is not permitted by statutory regulation or exceeds the permitted use, you will need to obtain permission directly from the copyright holder. To view a copy of this licence, visit http://creativecommons.org/licenses/by/4.0/. 